\title{
Resposta do cafeeiro à adubação potássica em safras de baixa e alta produção(1)
}

\author{
Enilson de Barros Silva( ${ }^{(2)}$, Francisco Dias Nogueira ${ }^{(3)}$, Paulo Tácito Gontijo Guimarães ${ }^{(3)}$ e Antônio Eduardo Furtini Neto ${ }^{(4)}$
}

\begin{abstract}
Resumo - Foram realizados dois experimentos em lavouras cafeeiras das Fazendas Experimentais da Epamig, em Minas Gerais, com o objetivo de estudar a resposta do cafeeiro à adubação potássica (fontes e doses) nas safras de baixa e alta produção em dois Latossolos. Os experimentos foram instalados em lavouras de café da cultivar Catuaí Vermelho, linhagem MG-99, plantadas seis anos antes, no espaçamento de 3,5 x 0,7 m. O delineamento experimental foi em blocos casualizados, com quatro repetições, no esquema de parcelas subdivididas. Nas parcelas, foram aplicadas as fontes de K: cloreto de potássio, sulfato de potássio e nitrato de potássio; e nas subparcelas, as doses de $\mathrm{K}(0,100$, 200 e $400 \mathrm{~kg} \mathrm{ha}^{-1}$ ). Foram avaliados a produção de grãos de café beneficiados, os teores de $\mathrm{K}$ disponível no solo (Mehlich-1) e nas folhas durante quatro safras (1995 a 1998): duas safras baixas (1995 e 1997), e duas altas (1996 e 1998), em ambos os solos. A resposta do cafeeiro às doses de K é diferenciada entre as safras de baixa e alta produção. A alternância de produção do cafeeiro mostra que, nessa cultura, os níveis críticos de $\mathrm{K}$ no solo e nas folhas devem ser obtidos em safras de alta produção.
\end{abstract}

Termos para indexação: Coffea arabica, rendimento, colheita, fertilidade do solo.

\section{Coffee tree response to potassium fertilization in low and high yields}

\begin{abstract}
In order to evaluate the response of coffee trees to potassium fertilization for low and high yield, two experiments were carried out in two Oxisols of Epamig Experimental Farms, in the Minas Gerais state, Brazil. The experiments were implanted in a field crop of the cultivar Catuaí Vermelho, line MG-99, which was planted six years ago at the spacing $3.5 \times 0.7 \mathrm{~m}$. The experiment was carried out in a randomized block design, with four repetitions in the split plot scheme. In the plots, $\mathrm{K}$ sources were applied: potassium chloride, potassium sulphate and potassium nitrate; and in the subplots, $\mathrm{K}$ doses $\left(0,100,200\right.$ and $\left.400 \mathrm{~kg} \mathrm{ha}^{-1}\right)$ were applied. Yield of processed coffee grains, available soil $\mathrm{K}$ (Mehlich-1) and leaf contents were determined in four crops (1995 to 1998): two crops for low yields (1995 and 1997) and two crops for high yields (1996 and 1998) in both soils. Coffee tree response to $\mathrm{K}$ doses was different between high and low yield. The yield alternation of coffee trees shows that critic levels of $\mathrm{K}$ in the soil and in the leaf contents should be obtained in high crops.
\end{abstract}

Index terms: Coffea arabica, yields, harvesting, soil fertility.

\section{Introdução}

Em decorrência da alternância anual de grande $\mathrm{e}$ pequena produção, a planta de cafeeiro extrai e exporta quantidades variáveis de nutrientes do solo

(1) Aceito para publicação em 20 de fevereiro de 2001 Financiado pela Fapemig e Consórcio Brasileiro de Pesquisa e Desenvolvimento do Café.

(2) Epamig-CTNM, Caixa Postal 12, CEP 39440-000 Janaúba, MG. E-mail: ebsilva@nortecnet.com.br

(3) Epamig-CTNM, Caixa Postal 176, CEP 37200-000 Lavras, MG. E-mail: fdias@lavras.br, paulotgg@ufla.br

(4) Universidade Federal de Lavras, Dep. de Ciência do Solo, Caixa Postal 37, CEP 37200-000 Lavras, MG. E-mail afurtini@ufla.br de um ano para outro. Embora a adubação dos cafezais geralmente seja feita com base na análise do solo e da folha e na carga pendente, deve-se verificar se existem diferenças de resposta à adubação potássica e nos teores de $\mathrm{K}$ disponível no solo e nas folhas entre safras de alta e de baixa produção.

Quanto à análise dos dados de produção, Stevens (1949) afirma que, no caso da alternância da produção, vários cuidados devem ser tomados nas análises estatísticas para que estes efeitos não prejudiquem as comparações que estão sendo estudadas nos experimentos. Sugere-se, ainda, que as análises das produções sejam feitas com a média de duas safras, separando-se safras de baixa e de alta produção do cafeeiro. Fraga Júnior \& Conagin (1956), ao 
fazerem a avaliação estatística de um ensaio de adubação, em Campinas, SP, em que se estudou a adubação orgânica, nitrogenada, fosfatada e potássica, observaram que, a partir do quarto ano, a produção passou a alternar-se em alta e baixa, e as análises foram feitas sempre considerando pares de ano. Cervellini \& Igue (1994), no Brasil, Jayarama et al. (1994), na Índia, fizeram suas interpretações utilizando dados médios das safras avaliadas.

Com relação à dose de $\mathrm{K}$ a aplicar em safras baixas e altas do cafeeiro, Viana et al. (1989) obtiveram maior produção quando foram empregadas doses mais elevadas nas safras baixas que influenciaram positivamente na colheita do ano seguinte. Por outro lado, as adubações feitas no ano, tiveram pouco efeito na produção. No entanto, Malavolta (1993) sugere que não se deve adubar menos em anos de safra baixa do cafeeiro, pois parte do K que a planta não utiliza para produção, ela a consome para poder vegetar.

Alguns trabalhos mostram a resposta do cafeeiro à aplicação de doses de $\mathrm{K}$, sem contudo levar em consideração a sua alternância de produção. Viana et al. (1985b) estudaram os efeitos de doses de K sobre a produção do cafeeiro Catuaí em um Latossolo Vermelho-Escuro. Aqueles autores encontraram resposta às doses de $\mathrm{K}$, e constataram que a maior produção foi obtida com $166 \mathrm{~kg} \mathrm{ha}^{-1}$ de K, com teor de K no solo de $126 \mathrm{mg} \mathrm{dm}^{-3}$, e foliar, de $13,6 \mathrm{~g} \mathrm{~kg}^{-1}$. Viana et al. (1985a), com a mesma cultivar e no mesmo tipo de solo, obtiveram produção máxima com a aplicação de $83 \mathrm{~kg} \mathrm{ha}^{-1}$ de $\mathrm{K}$, com teor no solo de $150 \mathrm{mg} \mathrm{dm}^{-3}$ de $\mathrm{K}$, e foliar, de $12,7 \mathrm{~g} \mathrm{~kg}^{-1}$ de $\mathrm{K}$. Já Viana et al. (1985c), utilizando a cultivar Mundo Novo, em um Latossolo Vermelho-Escuro, fase Cerrado, obtiveram a maior produção com $63 \mathrm{~kg} \mathrm{ha}^{-1} \mathrm{de} \mathrm{K}$, com teor de K no solo de $43 \mathrm{mg} \mathrm{dm}^{-3}$, e foliar, de $14,3 \mathrm{~g} \mathrm{~kg}^{-1}$ de K.

$\mathrm{Na}$ Índia, Jayarama et al. (1994) constataram, em um experimento conduzido por trinta anos para avaliação da adubação NPK no cafeeiro, que a produção máxima foi obtida com a aplicação de $180 \mathrm{~kg} \mathrm{ha}{ }^{-1}$ de K na forma de $\mathrm{KCl}$. No Brasil, Santinato et al. (1996) observaram, na variedade Acaiá, em Latossolo Vermelho-Amarelo, que a maior produção foi obtida com a dose de $176 \mathrm{~kg} \mathrm{ha}^{-1} \mathrm{de} \mathrm{K}$, na forma de nitrato de potássio, e teor foliar de $\mathrm{K}$, de $22 \mathrm{~g} \mathrm{~kg}^{-1}$.
Devido à alternância da produção do cafeeiro, torna-se difícil definir o teor adequado de $\mathrm{K}$ no solo. Porém, essa dificuldade é contornada pela análise dos dados, conforme citado por Stevens (1949) e Fraga Júnior \& Conagin (1956). Dessa forma, Guimarães (1986) obteve as faixas adequadas para o teor de K no solo em safras altas de 112 a $150 \mathrm{mg} \mathrm{dm}^{-3}$, e baixas, de $44 \mathrm{a} 60 \mathrm{mg} \mathrm{dm}^{-3}$. Malavolta (1986) destaca que a faixa adequada de $\mathrm{K}$ disponível no solo é de 117 a $156 \mathrm{mg} \mathrm{dm}^{-3}$, independentemente de safras de alta ou baixa produção do cafeeiro.

Guimarães (1986) não verificou a diferença entre o teor de K foliar em safras de baixa e alta produção do cafeeiro. Viana et al. (1985a, 1985b, 1985c) e Santinato et al. (1996) obtiveram somente o teor de K foliar para uma produção máxima, sem considerarem a alternância de produção do cafeeiro.

O objetivo deste trabalho foi avaliar a resposta do cafeeiro à adubação potássica (fontes e doses) em safras de baixa e alta produção.

\section{Material e Métodos}

Os experimentos foram realizados nas Fazendas Experimentais da Epamig, Minas Gerais, em Latossolo Vermelho (LV), de São Sebastião do Paraíso, e em Latossolo Vermelho-Amarelo (LVA) de Patrocínio, segundo Embrapa (1999). A classificação climática segundo Köppen é Cwa. As características químicas e físicas das amostras dos solos (0 a $20 \mathrm{~cm})$ em lavoura em produção encontram-se na Tabela 1 .

Tabela 1. Características químicas e físicas de amostras $(0$ a $20 \mathrm{~cm})$ dos dois $\operatorname{solos}^{(1)}$

\begin{tabular}{lcc}
\hline Características & $\begin{array}{r}\text { Latossolo } \\
\text { Vermelho }\end{array}$ & $\begin{array}{r}\text { Latossolo } \\
\text { Vermelho- } \\
\text { Amarelo }\end{array}$ \\
\hline $\mathrm{pH}($ água $)$ & 6,0 & 5,9 \\
$\mathrm{P}\left(\mathrm{mg} \mathrm{dm}^{-3}\right)$ & 7,0 & 3,0 \\
$\mathrm{~K}\left(\mathrm{mg} \mathrm{dm}^{-3}\right)$ & 70,0 & 63,0 \\
$\mathrm{Ca}\left(\mathrm{cmol}_{\mathrm{c}} \mathrm{dm}^{-3}\right)$ & 3,8 & 3,4 \\
$\mathrm{Mg}\left(\mathrm{cmol}_{\mathrm{c}} \mathrm{dm}^{-3}\right)$ & 0,9 & 1,3 \\
$\mathrm{Al}\left(\mathrm{cmol}_{\mathrm{c}} \mathrm{dm}^{-3}\right)$ & 0,1 & 0,1 \\
$\mathrm{CTC}$ efetiva $\left(\mathrm{cmol}_{\mathrm{c}} \mathrm{dm}^{-3}\right)$ & 5,0 & 5,0 \\
$\mathrm{CTC} \mathrm{a} \mathrm{pH} 7,0\left(\mathrm{cmol}_{\mathrm{c}} \mathrm{dm}^{-3}\right)$ & 7,5 & 7,1 \\
$\mathrm{~m}(\%)$ & 2,0 & 2,0 \\
$\mathrm{~V}(\%)$ & 65,0 & 69,0 \\
Matéria orgânica $\left(\mathrm{g} \mathrm{kg}^{-1}\right)$ & 26 & 31 \\
Areia $\left(\mathrm{g} \mathrm{kg}^{-1}\right)$ & 240 & 220 \\
Silte $\left(\mathrm{g} \mathrm{kg}^{-1}\right)$ & 230 & 310 \\
Argila $\left(\mathrm{g} \mathrm{kg}^{-1}\right)$ & 530 & 470 \\
\hline (1)Laboratório de Fertilidade e Física do Solo - DCS/Ufla Lavras, MG
\end{tabular}


Usaram-se, em ambos os locais, cafezais da espécie Coffea arabica L., da cultivar Catuaí Vermelho, linhagem MG-99, com idade de seis anos, com uma planta por cova, no espaçamento de $3,5 \times 0,7 \mathrm{~m}$. O delineamento experimental empregado foi o de blocos ao acaso, em parcelas subdivididas, com quatro repetições. Nas parcelas, foram utilizadas três fontes de $\mathrm{K}$ : cloreto de potássio $(\mathrm{KCl})$, sulfato de potássio $\left(\mathrm{K}_{2} \mathrm{SO}_{4}\right)$ e nitrato de potássio $\left(\mathrm{KNO}_{3}\right)$, e nas subparcelas, quatro doses de $\mathrm{K}(0,100,200$ e $\left.400 \mathrm{~kg} \mathrm{ha}^{-1}\right)$. A parcela experimental foi constituída de três linhas de oito covas, formando um total de vinte e quatro covas por parcela, sendo a parcela útil constituída pelas seis covas centrais.

A adubação nitrogenada (uréia) e fosfatada (superfosfato tripo) foi aplicada em doses recomendadas para lavoura do mesmo porte e idade, segundo Guimarães et al. (1999) As doses de $\mathrm{K}$ de cada fonte e a adubação básica ( $\mathrm{N}$ e $\mathrm{P}$ ) foram parceladas em quatro doses iguais, a cada ano. A cada safra, foram aplicadas, em dezembro, via solo, $10 \mathrm{~g}$ de bórax ( $11 \%$ de B) por cova, e via foliar, solução a 0,5 e $0,3 \%$ de ácido bórico e sulfato de zinco, respectivamente, para o controle preventivo de deficiências, além dos controles fitossanitários e tratos culturais.

Foi avaliada a produção de grãos das seis covas úteis, colhidos por derriça no pano, quando apresentaram aproximadamente $5 \%$ de frutos verdes. As amostras foram secadas em terreiro cimentado, pesadas e beneficiadas. A quantidade de café beneficiado, por parcela útil, foi convertida em produção de sacas de $60 \mathrm{~kg}$ por hectare As produções foram avaliadas por quatro safras (1995 a 1998), em cada local de cultivo, e as safras foram baixas em 1995 e 1997, e altas em 1996 e 1998

As análises de solo foram feitas em amostras retiradas antes da arruação na faixa adubada, na profundidade de 0 a $20 \mathrm{~cm}$ (Malavolta, 1992), com seis subamostras, para formar uma amostra composta por parcela útil, para determinação do teor de K disponível, pelo método de Mehlich-1.

Quanto à determinação do teor de K nas folhas, foram colhidos o terceiro e o quarto pares de folhas a partir das pontas dos ramos laterais, inseridos na altura média da planta e ao redor desta, no verão, nas quatro safras, em cada local de cultivo (Malavolta, 1993). O teor de K nas folhas foi determinado no extrato obtido por digestão nitroperclórica, e dosado por fotometria de chama (Malavolta et al., 1997)

Os dados de produção de grãos de café beneficiados, e os teores de $\mathrm{K}$ nas folhas e disponível no solo foram submetidos a análise de variância conjunta, e constaram dos fatores: blocos, fontes de $\mathrm{K}$, doses de $\mathrm{K}$, tipo de solo e safras de baixa e alta produção. As equações foram ajustadas à produção de grãos de café benefíciados, para média das safras baixas (1995 e 1997) e altas (1996 e 1998), em razão das doses de $\mathrm{K}$ aplicadas, em ambos os solos. A partir das equações obtidas, estimaram-se as doses para máxima produção de grãos de café beneficiados.

Os teores de $\mathrm{K}$ disponíveis no solo e nas folhas, necessários à obtenção da produção máxima, foram estimados por meio das equações que relacionam a produção de café, com seus teores no solo e na folha, em ambos os solos.

\section{Resultados e Discussão}

Houve efeito significativo da interação tipo de solo, safra de café em baixa e alta produção e doses de K (Tabela 2). Houve resposta do cafeeiro à aplicação de K (Figura 1). Resultados semelhantes foram obtidos por Viana et al. (1985a, 1985b, 1985c), Viana et al. (1989), Jayarama et al. (1994) e Santinato et al. (1996). Os teores de K do LV e do LVA foram, respectivamente, 70 e $63 \mathrm{mg} \mathrm{dm}^{-3}$ (Tabela 1). Essa resposta confirma os dados de Alvarez Viegas et al. (1999), segundo os quais existe grande probabilidade de resposta do cafeeiro à adubação potássica quando o teor médio de $\mathrm{K}$ estiver dentro da faixa de 41 a $70 \mathrm{mg} \mathrm{dm}^{-3}$. Além disso, o cafeeiro é bastante exigente em K (Malavolta, 1986, 1993).

A produção máxima de grãos de café beneficiados não foi alcançada com a dose máxima aplicada de $\mathrm{K}\left(400 \mathrm{~kg} \mathrm{ha}^{-1}\right)$ na safra de baixa produção, nos dois tipos de solo (Figura 1). Por outro lado, na safra de alta produção, a produção máxima foi alcançada com 205,6 e 209, $4 \mathrm{~kg} \mathrm{ha}^{-1}$ de K, no LV e LVA, respectivamente. Essas doses de $\mathrm{K}$ foram superiores às determinadas por Viana et al. (1985a, 1985b, 1985c), Jayarama et al. (1994) e Santinato et al. (1996) para atingirem produções máximas na safra de alta produção. Portanto, a dose de K nas safras de baixa produção foram mais elevadas do que nas safras de alta produção, em ambos os solos. Este comportamento deve-se à maior absorção e, conseqüentemente, maior exportação de nutrientes pela safra de alta produção que necessitam ser restituídos na safra de baixa produção para garantir a colheita seguinte. Resultados semelhantes foram obtidos por Viana et al. (1989). Corroborando esses resultados, Malavolta (1993) e Guimarães et al. (1999) recomendam que a adubação potássica na safra de baixa produção seja mais elevada do que na safra de alta produção. 
Tabela 2. Resumo da análise de variância da análise conjunta para produção, teor de K disponível no solo (Mehlich-1) e foliar.

\begin{tabular}{lcccc}
\hline Fonte de variação & Grau de liberdade & Produção de café & K disponível no solo & K nas folhas \\
\hline Bloco (Solo) & 6 & 35,97 & 305,15 & 2,06 \\
Solo (S) & 1 & $11.125,97^{* *}$ & $70.005,33^{* *}$ & $118,68^{* *}$ \\
Fonte (F) & 2 & 3,49 & $1.742,77^{*}$ & $107,50^{* *}$ \\
S x F & 2 & 12,43 & $4.230,02^{* *}$ & 0,55 \\
Erro (a) & 12 & 70,89 & 373,69 & 2,54 \\
\hline Doses de K (D) & 3 & $489,27^{* *}$ & $223.898,31^{* *}$ & $172,77^{* *}$ \\
S x D & 3 & 42,21 & $8.369,06^{* *}$ & $15,70^{* *}$ \\
F x D & 6 & 34,82 & $1.032,93$ & 1,90 \\
S x F x D & 6 & 55,35 & $1.100,55$ & 1,76 \\
Erro (b) & 23,44 & 457,01 & 1,79 \\
\hline Safra de café (SC) & 1 & $80.640,86^{* *}$ & $3.673,25^{* *}$ & $526,59^{* *}$ \\
S x SC & 1 & $1.010,21^{* *}$ & 426,62 & $31,89^{* *}$ \\
F x SC & 50,09 & $1.703,88^{*}$ & 1,11 \\
D x SC & $144,56^{* *}$ & $1.180,86^{*}$ & $9,61^{* *}$ \\
S x F x SC & 2 & 43,23 & 311,75 & 0,65 \\
S x D x SC & 3 & $87,35^{*}$ & $2.039,03^{* *}$ & $21,07^{* *}$ \\
F x D x SC & 2 & 28,11 & 534,39 & 2,00 \\
S x F x D x SC & 3 & 10,18 & 429,23 & 2,79 \\
Erro (c) & 6 & 29,24 & 363,43 & 1,59 \\
\hline Média Geral & 6 & 42,56 & 134,29 & 17,08 \\
CV (a) & 17 & 19,78 & 14,39 & 9,32 \\
CV (b) & & 11,37 & 15,92 & 7,83 \\
CV (c) & & 12,70 & 14,19 & 7,39 \\
\hline
\end{tabular}

* e **Significativo a $5 \%$ e a $1 \%$ de probabilidade, respectivamente, pelo teste $\mathrm{F}$.
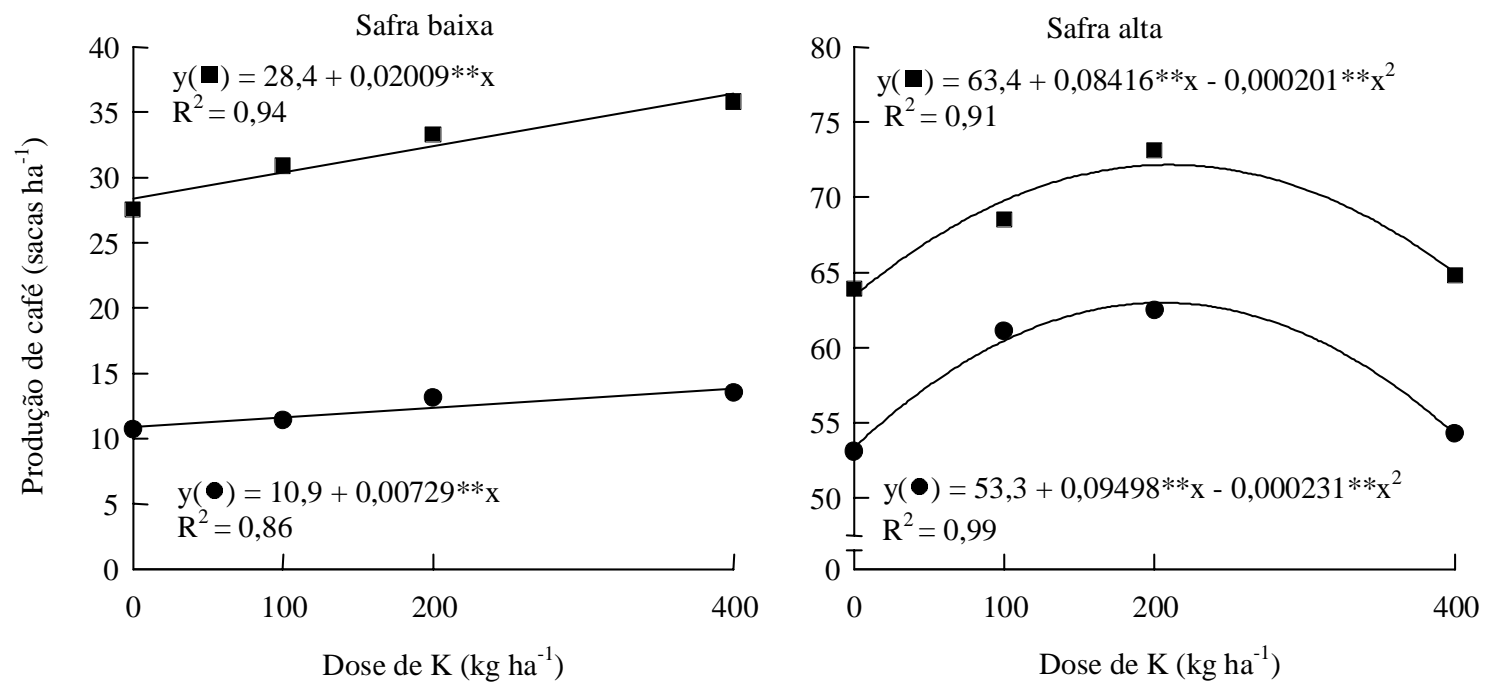

Figura 1. Relação entre produção de café e doses de K na safra baixa e alta do Latossolo Vermelho (•) e Latossolo Vermelho-Amarelo $(\mathbf{m})(* *$ Significativo a $1 \%$ de probabilidade pelo teste $\mathrm{t})$. 
Como na safra baixa a produção de café em relação às doses de $\mathrm{K}$ aplicadas foi linear, ou seja, a maior dose de $\mathrm{K}$ usada não foi suficiente para atingir a produção máxima (Figura 1), os níveis críticos de K

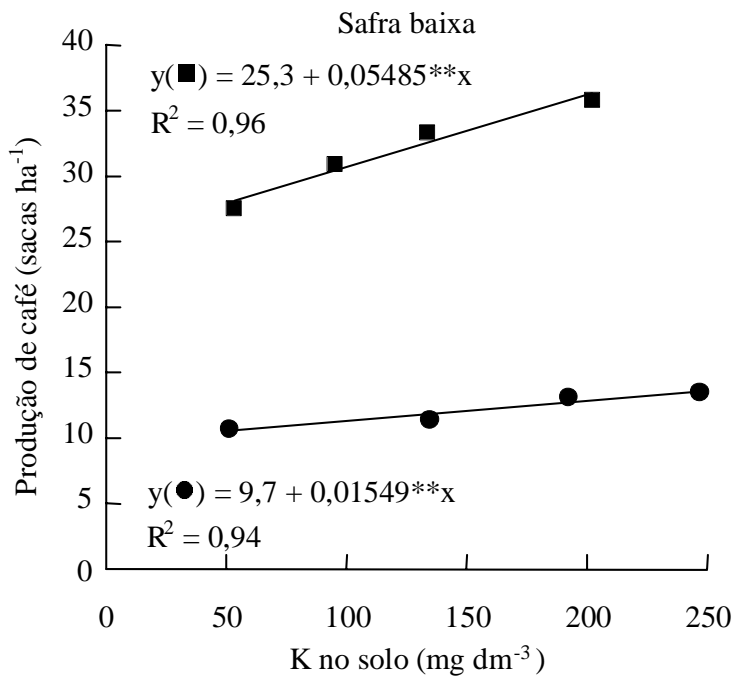

no solo (Figura 2) e na folha (Figura 3) não puderam ser determinados. Por outro lado, na safra de alta produção, os teores de $\mathrm{K}$ no solo necessários para obtenção da produção máxima foram de 155,7 e

Figura 2. Relação entre produção de café e o teor de $\mathrm{K}$ disponível (Mehlich-1) na safra baixa e alta do Latossolo Vermelho $(\bullet)$ e Latossolo Vermelho-Amarelo (- (**Significativo a $1 \%$ de probabilidade pelo teste F).
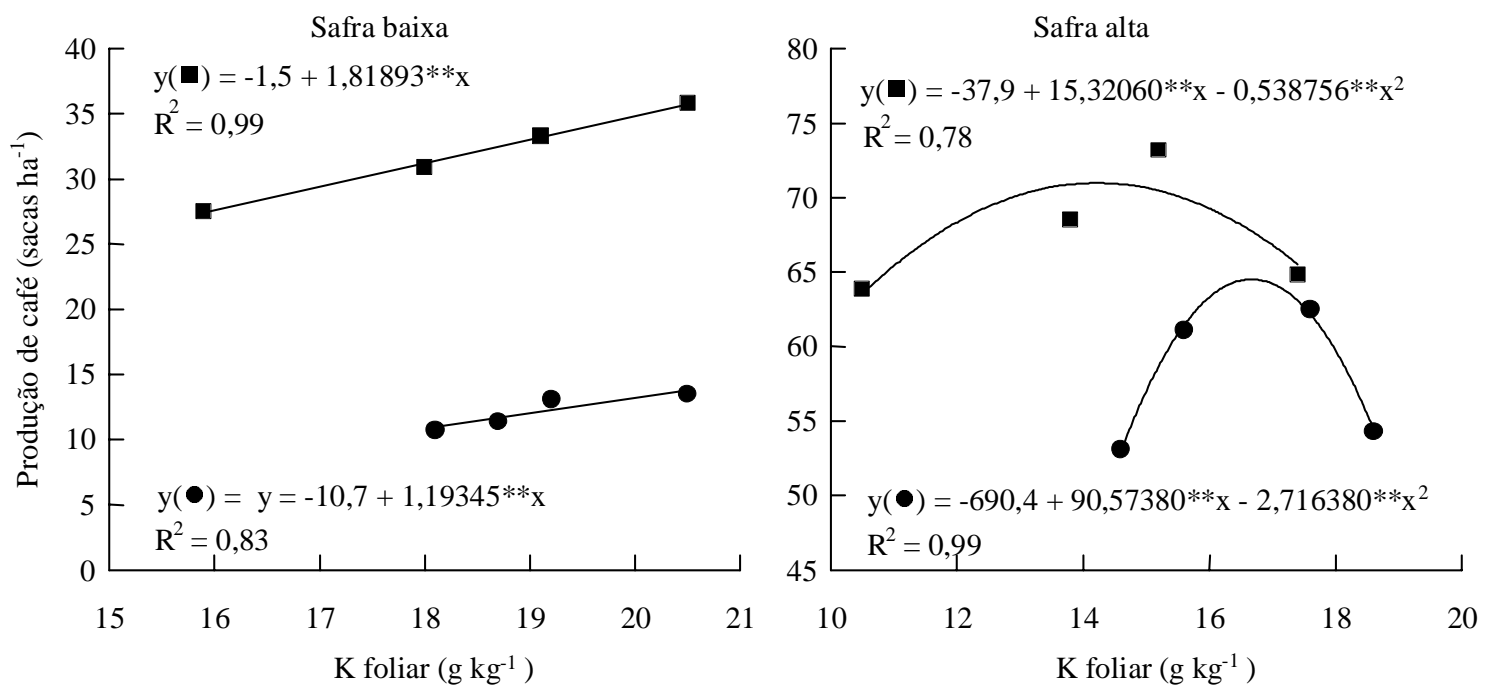

Figura 3. Relação entre a produção de café e o teor de K na folha na safra baixa e alta do Latossolo Vermelho (•) e

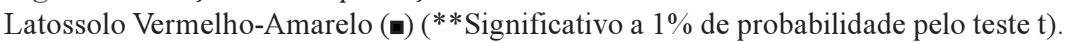


$110,4 \mathrm{mg} \mathrm{dm}^{-3}$ (Figura 2), e nas folhas, de 16,7 e $14,2 \mathrm{~g} \mathrm{~kg}^{-1}$ (Figura 3) nos cafeeiros plantados em LV e LVA, respectivamente. Os teores médios de $\mathrm{K}$ nos dois solos foram de $133,1 \mathrm{mg} \mathrm{dm}^{-3}$ no solo, e $15,5 \mathrm{~g} \mathrm{~kg}^{-1}$, nas folhas.

Os teores máximos médios de $\mathrm{K}$ disponível no solo obtidos na alta safra do cafeeiro estão dentro da faixa adequada proposta por Malavolta (1986) e determinada por Guimarães (1986) em cafeeiro. Os teores máximos médios de $\mathrm{K}$ nas folhas estão acima do encontrado por Viana et al. (1985a, 1985b, 1985c), abaixo do obtido por Santinato et al. (1996), e considerados marginais, conforme Malavolta (1993).

\section{Conclusões}

1. A resposta do cafeeiro a doses de K é diferenciada entre as safras de baixa e alta produção.

2. A determinação dos níveis críticos de $\mathrm{K}$ no solo e nas folhas deve ser feita em safras de alta produção, por causa da alternância de produção do cafeeiro.

\section{Referências}

ALVAREZ VIEGAS, V. H.; NOVAIS, R. F.; BARROS, N. F. de; CANTARUTTI, R. B.; LOPES, A. S. Interpretação dos resultados das análises de solos. In: RIBEIRO, A. C.; GUIMARÃES, P. T. G.; ALVAREZ VIEGAS, V. H. (Ed.). Recomendações para o uso de corretivos e fertilizantes em Minas Gerais: $5^{\mathfrak{a}}$ aproximação. Viçosa, MG Comissão de Fertilidade do Solo do Estado de Minas Gerais, 1999. p. 25-32

CERVELLINI, G. S.; IGUE, T. Adubação mineral e orgânica do cafeeiro. Bragantia, Campinas, v. 53, n. 1, p. $83-$ 93, 1994

EMBRAPA. Centro Nacional de Pesquisa de Solos (Rio de Janeiro, RJ). Sistema brasileiro de classificação de solos. Brasília: Embrapa-SPI, 1999. 412 p.

FRAGA JÚNIOR, C. G.; CONAGIN, A. Delineamentos e análises de experimentos com cafeeiros. Bragantia, Campinas, v. 15, n. 17, p. 177-191, 1956.

GUIMARÃES, P. T. G. Respostas do cafeeiro (Coffea arabica L. cv. Catuaí) à adubação mineral e orgânica em solos de baixa fertilidade do sul de Minas Gerais. Piracicaba: Esalq, 1986. 140 p. Tese de Doutorado.
GUIMARÃES, P. T. G.; GARCIA, A. W. R.; ALVAREZ VIEGAS, V. H.; PREZOTTI, L. C.; VIANA, A. S.; MIGUEL, A. E.; MALAVOLTA, E.; CORRÊA, J. B.; LOPES, A. S.; NOGUEIRA, F. D.; MONTEIRO, A. V. C. Cafeeiro. In: RIBEIRO, A. C.; GUIMARÃES, P. T. G.; ALVAREZ VIEGAS, V. H. (Ed.). Recomendações para o uso de corretivos e fertilizantes em Minas Gerais: 5a aproximação. Viçosa, MG: Comissão de Fertilidade do Solo do Estado de Minas Gerais, 1999. p. 289-302.

JAYARAMA, R. P.; ALWAR, A.; NAIDU, R. Latest concept of fertilizer usage in coffee plantations with respect to nitrogen, phosphorus and potassium. Indian Coffee, Bangalore, v. 58, n. 9, p. 9-12, 1994

MALAVOLTA, E. ABC da análise de solos e folhas São Paulo: Ceres, 1992. 124 p.

MALAVOLTA, E. Nutrição, adubação e calagem para o cafeeiro. In: RENA, A.B.; MALAVOLTA, E.; ROCHA, M.; YAMADA, T. (Ed.). Cultura do cafeeiro: fatores que afetam a produtividade. Piracicaba: Potafos, 1986. p. $136-274$

MALAVOLTA, E. Nutrição mineral e adubação do cafeeiro: colheitas econômicas máximas. São Paulo: Agronômica Ceres, 1993. 210 p.

MALAVOLTA, E.; VITTI, G. C.; OLIVEIRA, S. A. Avaliação do estado nutricional das plantas: princípios e aplicações. Piracicaba: Potafos, 1997. 201 p

SANTINATO, R.; OLIVEIRA, L. H.; PEREIRA, E. M Efeitos do uso de salitre de potássio como fonte de nitrogênio e potássio na adubação química do cafeeiro Carmo do Paranaíba, MG - 1992/1996. In: CONGRESSO BRASILEIRO DE PESQUISAS CAFEEIRAS, 22., 1996, Águas de Lindóia. Anais... São Paulo: Ministério daAgricultura e do Abastecimento, 1996. p. 180-184

STEVENS, W. L. Análise estatística do ensaio de variedades de café. Bragantia, Campinas, v. 9, p. 103-123, 1949

VIANA, A. S.; GARCIA, A. W. R.; CORRÊA, J. B.; MATA, J. M. Estudo de níveis e relação N/K em cafeeiros plantados em solo LE. In: CONGRESSO BRASILEIRO DE PESQUISAS CAFEEIRAS, 12., 1985, Caxambu. Anais... Rio de Janeiro: IBC-Gerca, 1985a. p. 139-142.

VIANA, A. S.; GARCIA, A. W. R.; LACERDA, M. P.; FIORANTE, N. Níveis e relação N/K em cafezais planta- 
dos em espaçamento 2 x 1m. In: CONGRESSO BRASILEIRO DE PESQUISAS CAFEEIRAS, 12., 1985, Caxambu. Anais... Rio de Janeiro: IBC-Gerca, 1985b. p. 66-69

VIANA, A. S.; MIGUEL, A. E; CORRÊA, J. B.; LACERDA, M. P.; FIORANTE, N. Doses de parcelamento de adubação nitrogenada e potássica para formação e produção do cafeeiro em solo de cerrado. In
CONGRESSO BRASILEIRO DE PESQUISAS CAFEEIRAS, 12., 1985, Caxambu. Anais... Rio de Janeiro: IBC-Gerca, 1985c. p. 146-148.

VIANA, A. S.; MIGUEL, A. E.; MATA, J. M. Adubação do cafeeiro em função do ciclo bienal em solo LEd. In: CONGRESSO BRASILEIRO DE PESQUISAS CAFEEIRAS, 15., 1989, Maringá. Anais ... Rio de Janeiro: IBC-Gerca, 1989. p. 150-153 